\title{
CONTROLLING IRON DEFICIENCY
}

\section{Editorial Introduction}

\author{
The Ceylon Journal of Medical Science 1999; 42: 27-28
}

Iron deficiency is the commonest nutritional disorder in the world, affecting particularly reproductive women and pre-school children. It also has a serious impact on school children and workers. If uncorrected, it leads to anaemia of increasing severity, reduction in work capacity, diminished learning ability, increased susceptibility to infection and greater risk of death, associated with pregnancy and childbirth $(1,2)$.

Iron deficiency results from consuming diets containing insufficient iron, with reduced iron availability, increased iron requirements to meet reproductive demands and losses due to parasitic infections; these factors often operate concurrently (1).

,The National Nutrition and Health Survey conducted by the Ministry of Plan Implementation in 1995. showed that anaemia was widespread in Sri Lanka, prevalence being high in all sectors of the population - infants, pre-schoolers, preadolescents and adolescents, menstruating women and pregnant women (3).

The national strategies for reducing the prevalence of anaemia are largely confined to pregnant women due to the emphasis placed on reducing intra-uterine growth retardation and the percentage of low birth weight babies. There is also an appropriate information, education and communication (IEC) strategy, specific attention being given to training of all categories of health workers. Another component of the strategy is control of worm infestations associated with anaemia.

The Ministry of Plan Implementation therefore deemed it important to develop programmes to cover other vulnerable segments of populations and to extend the existing programmes, so as to improve the iron status of the entire population.

The issues addressed could be grouped under 4 headings:

\section{Training and IEC}

i. Identification of institutions involved in IEC activities and the level and extent of anaemiarelated training, and a review of messages.

ii. Determine the effectiveness of present training and IEC programmes.

iii. Development of a standardised monitoring system.

\section{Food-based interventions}

i. Review of existing Laws and Regulations pertaining to the addition of micro nutrients to foods.

ii. Develop a quality assurance system for iron fortified wheat flour

iii. Review of fortified foods in the market

3. Supply and demand for anaemia-related supplements

i. Data collecting, analyses and report

ii. Determine the potential to distribute anaemiarelated supplements through schools

iii. Determine the potential and options for distributing the iron supplements through the work place 


\section{Monitoring effectiveness of anaemia-related interventions}

i. Review of what is known about the cost and effectiveness of current programmes including malaria and helminth control as they relate to anaemia

ii. Review the bioavailability of Ayurveda preparations for iron supplementation

These eleven activities were given to nine consultants who were funded by the USAID, through OMNI. Due to delays in the Ministry, the consultants had less than three months to complete their tasks. Their reports will be published by the Ministry. In this issue of the Journal we publish abbreviated versions of some of these reports.

\section{T. W. Wikramanayake \\ R. L. Jayakody \\ Co-editors}

\section{References}

1. Gillespie S, Kevang J, Mason J (Eds.). Controlling Iron Deficiency. A report based on an ACC/SCN workshop. ACC/SEN state- of the- art series, Nutrition Policy Discussion Paper No.9. Geneva: WHO 1991.

2. Wikramanayake T. W. Combating Iron Deficiency, Editorial Introduction. Ceylon Journal of Medical Science 1996; 39: 1-8.

3. Mudalige R, Nestle P. Prevalence of anaemia in Sri Lanka. Ceylon Journal of Medical Science 1996; 39: 9-16. 